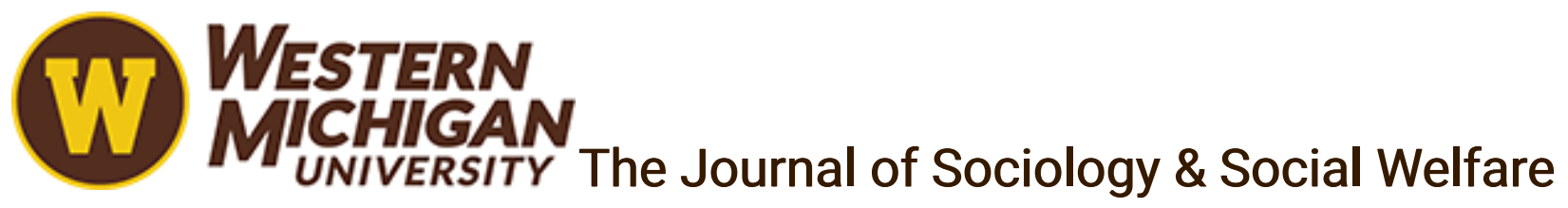

Volume 8

Issue 2 July

Article 10

July 1981

\title{
Toward a Model of Factors Influencing the Hiring of Women with a History of Breast Cancer
}

Nancy McCharen

University of North Carolina, Chapel Hill

Jo Anne L. Earp

University of North Carolina, Chapel Hill

Follow this and additional works at: https://scholarworks.wmich.edu/jssw

Part of the Clinical and Medical Social Work Commons, and the Social Work Commons

\section{Recommended Citation}

McCharen, Nancy and Earp, Jo Anne L. (1981) "Toward a Model of Factors Influencing the Hiring of Women with a History of Breast Cancer," The Journal of Sociology \& Social Welfare: Vol. 8 : Iss. 2 , Article 10.

Available at: https://scholarworks.wmich.edu/jssw/vol8/iss2/10 
TOWARD A MODEL OF FACTORS INFLUENCING THE HIRING OF WOMEN WITH A HISTORY OF BREAST CANCER ${ }^{1}$

Nancy McCharen, M.P.H. and Jo Anne L. Earp, Sc.D. Department of Health Education, School of Public Health University of North Carolina at Chapel Hill, North Carolina

\begin{abstract}
Whether surgical treatment for cancer which results in the removal of an external part of the body is viewed by employers as a medical disability that interferes with the performance of job-related functions, or fits a more stereotypic definition of a physical handicap that might even prevent an employee from being hired, has not been adequately studied. To identify factors which influence employers' decisions to hire women who have had breast cancer, a model of factors influencing the decision to hire was developed. A random sample of personnel directors from an industrialized North Carolina county was surveyed. A majority had personal experience with breast cancer patients and had had mastectomy employees leave work. Five factors were found to explain $69 \%$ of the variance in hiring practices: size of company, level of sick leave benefits, company involvement in employees' medical insurance, employers' education and personal experience with breast cancer. Knowledge level about the disease did not predict the hiring decision. Regardless of whether medical personnel made the final decision, the influence of non-medical factors was found to be quite strong in determining whether a former breast cancer patient was actually hired.
\end{abstract}

\title{
Introduction
}

Only a very few studies have been conducted on employer hiring practices for persons with cancer or other chronic disease conditions

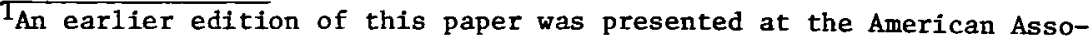
ciation of Public Opinion Research (AAPOR) in Roanoke, Virginia, June, 1978. Special thanks go to two anonymous reviewers for their constructive critiques on the organization of the paper in manuscript form.
} 
from the perspective of the employer, rather than from that of the patient or job applicant (Reynolds, 1977). Instead, patients' perceptions of the effect of their illness on employment opportunities--either anticipated or experienced--have usually been relied upon (Craig, et al, 1974; Schottenfeld and Robbins, 1970).

The dual foci of the study reported on here was to: 1) describe the employment situation for women with a history of breast cancer and 2) test selected aspects of a conceptual model of factors thought to influence employers either to hire or not to hire women with a history of breast cancer. A review of the available literature directly bearing on the subject of employment of women with breast cancer as well as of more tangentially-related research on employer attitudes and practices toward employees generally considered handicapped or disabled gave rise to the theoretical model shown in Fig. 1. The specific factors in the model tested in the empirical research reported on here were the relationships among: company factors (非), company policies (\#5), the employer (\#6) and actual hiring (\#9). (Fig. 1 on next page)

Background

Medical condition, when it is considered in the hiring process, operates most of ten as a negative factor, a reason not to hire someone. Initially, employers are influenced by cultural images of, and attitudes toward, particular illnesses. Jenkins and Zyzanski (1968) found, in an urban Florida county, that most people associate cancer with helplessness and perceive it as stigmatizing. Wakefield (1970), in numerous studies on attitudes toward cancer, notes a persistence of beliefs about its incurability and gruesome mortality. He found that nurses had an exaggerated pessimism towards cancer patients, based on their personal experience rather than on their professional training.

Legislation reflects general societal attitudes as well. While specialized legislation, such as vocational rehabilitation or affirmative action programs, may affect positively the ultimate decision to hire a woman with a history of breast cancer, it can also result in labeling. This, in turn, may contribute to the formation of social stigmas that restrict those people to certain kinds of jobs or set quotas on the number of such people able to be hired.

Categorical legislation, while providing protection to former cancer patients, may also result in labeling and social stigma for those protected. The Vocational Rehabilitation Act of 1973 pertaining to the handicapped can be interpreted as including former cancer patients (Tokarski, et al, 1976). Both New York (1973) and California 


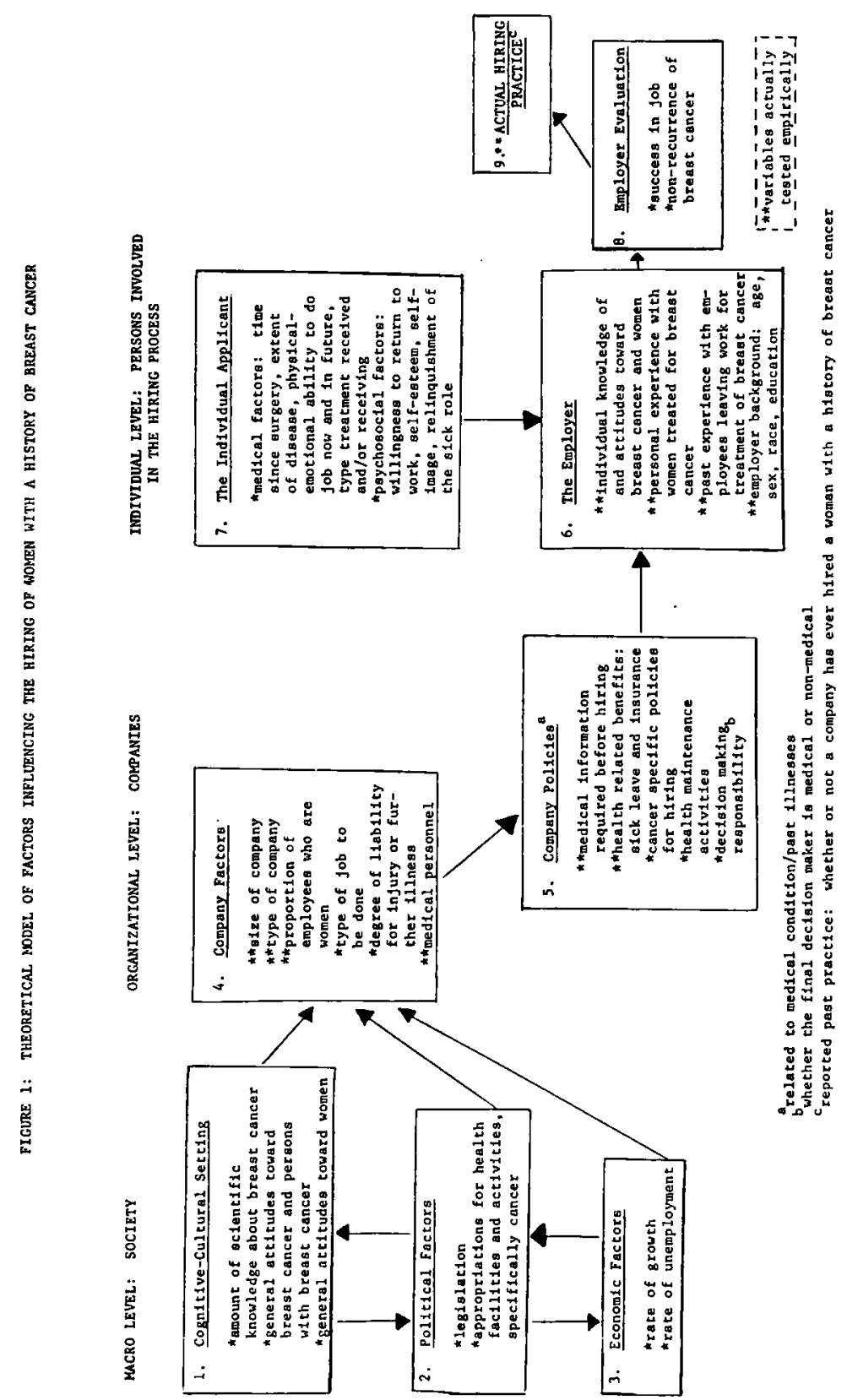


(1975) include former cancer patients in state labor codes prohibiting employment discrimination. To date, any stigmatizing impact as well as assessment of the benefits of such legislation has not been reported in the literature.

Attitudes related to factors within business organizations have also been shown to serve as deterrents to hiring individuals with particular medical histories. McKenna (1974) cites such fears as that the employee may need great amounts of sick leave, may cause an increase in health insurance for all employees, may cause workmen's compensation to increase. However, he does not test the validity of these suppositions.

In a survey of 125 industrial physicians, Weinstock and Haft (1974) found that though willingness to hire a person with chronic ailments varied with the type of illness and the kind of position applied for, factors such as company liability for further illness, possible increase in cost of compensation insurance and possible loss in work time also influenced the decision to hire. They conclude that "The criteria used for determining employability appear, in some cases, to have little relation to modern medical judgement." (p. 83).

Organizations debate the utility of a preplacement physical examination versus a medical history questionnaire completed by the applicant (Williamson, 1971; Voelz and Spiekard, 1975). But few question the requirement that medical information is necessary for hiring. Contrary to the beliefs of many employers, however, at least one researcher has shown that preemployment medical ratings are poor predictors of later job performances, at least in non-hazardous positions. In a double blind study of a medically nonrestrictive hiring policy, Alexander et al $(1975,1977)$ found, at one year, no significant differences on number of days out of work for sickness or in quality of work performance between those labeled "no medical risks" regardless of actual condition and those labeled as "risks" on the basis of actual medical conditions. They concluded that preplacement employment physicals are not cost beneficial.

Indeed Feldman (1978) notes that former cancer patients took fewer sick leave days and worked harder than other employees, probably to combat employer and co-worker expectations of poor performance and absenteeism. A study done by the Metropolitan Life Insurance Company suggests that the work performance of cancer patients is no different from that of other employees (Wheatley, et al, 1974). 


\section{The Model}

The above findings gave rise to the theoretical model proposed in Fig. 1. Factors external to the job applicant but considered influential in affecting employer practices for women with a history of breast cancer were identified on three levels: Macro (Society); Organizational (Companies), and Individual (Persons involved in the hiring process).

On the basis of the model it was hypothesized that the employer, building on his/her own personal knowledge and experience and influenced, in addition, by societal factors shaping attitudes toward disease and disability, takes into consideration specific company policies as well as an individual applicant's condition before arriving at an evaluation of the applicant's potential. The applicant is then either hired or not hired based on that employer's evaluation. On the basis of cost considerations and other practical considerations, only four parts of the model were actually tested in the research reported on here: Company Factors (\#4), Company Policies (\#5), The Employer (\#6) and Actual Hiring Practice ( $\$ 9$ ). The latter concept served as the dependent variable in this research; it was operationalized as "reported past employment practices regarding the hiring of women known to have a history of breast cancer."

\section{Methodology and Study Design}

Though primarily a descriptive study using a cross-sectional design, provisions were made to tentatively test associations among a number of variables included in the model. The survey took place in 1977 in an industrial county in central North Carolina. Fifty-seven percent of the women age 16 and over in the county in that year were in the labor force. For women age 45 to 64 (i.e., those most likely to develop breast cancer), $63 \%$ were in the labor force. Hence, it was assumed that many, if not most, large companies had been exposed to women employees with a history of breast cancer, either those already on the job or those seeking a new position.

The population for the survey was all employers in the county. The term "employers" was used in this research to refer to those persons responsible for hiring job applicants. Thus the unit of observation was an individual rather than a company. Respondents were mostly experienced, college-prepared, white, middle-aged, upper and middle level management personne1, $79 \%$ of whom were male.

Two sampling frames, one industrial (125 companies) and one non- 
industrial ( 73 establishments) were used to obtain a random sample of all places of business in the county. The only exclusions from the sample were those establishments whose work force numbered fewer than 25 employees or whose employee population was totally male.

A $50 \%$ sample from each frame was randomly selected. Eleven places had to be eliminated, some no longer in business, others because they did not meet the size or sex-specific criteria used for inclusion in this study. Eighty-seven self-administered anonymous questionnaires were distributed to the individual in each company responsible for making the final hiring decisions; 68 were returned for a $78 \%$ response rate.

The procedure used to deliver the questionnaires included several steps so as: 1) to assure us that the respondents did, in fact, meet the definition of employer and 2) to obtain as high a response rate as possible. Introductory letters to each company were followed up by telephone calls to confirm that the company met the requirements for inclusion in the study and that the individual receiving the letter satisfied the definition of employer. The researchers then visited each company to answer general questions the participants might have about the study and to leave the questionnaire along with a stamped envelope. A week after the visit, follow-up letters were sent to all participants.

The 68 returned questionnaires represented $34 \%$ of the combined sampling frames. However, the final sample size for analyses involving the dependent variable question "To your knowledge, has your company ever hired a new employee with a history of breast cancer?" was smaller than 68 because of the "don't know" responses. (The responses were: 29\% "no"; $25 \%$ "yes"; $46 \%$ "don't know"). Because questionnaires were anonymous, it was impossible to follow-up the "don't know" responses in order to classify them as either "yes" or "no". Thus we took the conservative position and discarded them, reducing the sample size to 37 for analyses involving that variable. Although the study was an exploratory one, multivariate analytical techniques were used despite the small sample size; relationships that emerged from such procedures, we reasoned, would have to be very strong in order to reach statistical significance.

As indicated earlier, correlations between hiring practice and selected variables in three of the eight different categories of the model were examined. Of the 19 variables originally hypothesized to be related to hiring practice, several were dropped before analysis (e.g., explicit cancer policy and race of decision-maker) because 
of insufficient variation in their distributions. Others were not included in the series of multiple stepwise regressions subsequently performed because they were not significantly related $(p<.05)$ to hiring practice in bi-variate analyses. Of the remaining 13 independent var1ables, a two-stage series of stepwise regressions with hiring practice revealed eight to be strong predictors of past practice. These 8 were then tested in a final regression model.

\section{$\underline{\text { Results }}$}

Corresponding to the two major objectives set forth in the Introduction, the results are divided into two sections. In the first the employment situation, including characteristics of the companies, company policies and characteristics of the employer-respondents themselves, is described; all variables initially expected to influence the decision to hire or not to hire women with a history of breast cancer are defined. In the second part of this section, an analysis of the relationships between the dependent variable and selected independent and interviewing variables is presented in an attempt at assessing more specifically the utility and validity of particular components of the theoretical model shown in Fig. 1.

\section{Characteristics of the companies: (Factor 非)}

More than two thirds of the 68 companies participating in the study were manufacturing plants; the remainder were businesses engaged in performing services, or in trade, transportation, finance or government work. Businesses ranged in employee size from 25 to 5000 , with 170 the median number of employees per establishment. About $60 \%$ of the companies had a majority female workforce. Fewer than haIf had their own, on-site medical personnel company doctors or occupational nurses.

\section{Company Policies relating to breast cancer: (Factor \#5)}

Fifty-five percent of the companies surveyed required medical histories of applicants before emloyment. Of these, $70 \%$ required preemployment physicals.

\section{Sick Leave}

The majority of respondents reported that sick leave benefits were affected most by length of service. Thirty-four percent said that type of job affected sick leave benefits while only $13 \%$ reported that type illness affected such benefits. 
In $44 \%$ of the cases, the minimum qualification for sick leave was either no days or fewer than five days. In contrast, in more than onethird of the cases for those considered "minimally" qualified, more than 11 sick leave days were allowed. For employees with the maximum qualification for paid sick leave, only one-third of the companies allowed either no days or five or fewer days. Over half the respondents reported that for employees with the maximum qualifications for sick leave, 11 or more days annually were allowed. Clearly, the definitions of "minimum" and "maximum" sick leave, as we11 as of "qualified" employee, varied widely in this sample. This variation foreshadowed the importance of the sick leave factor in the multivariate analysis used to test the conceptual model of hiring practices.

Medical Insurance for Employees

In only $6 \%$ of the cases was the company totally uninvolved in employees' medical insurance (to cover hospital and doctor charges) for those working full time. By contrast, $40 \%$ reported that the company paid the entire premium and all employees were covered. Fifty-four percent said that the company paid part of the premium for all (or some) employees and employees paid the other part.

Only three people said that their insurance prevented them from hiring individuals with particular medical histories (specifically heart, lung and skin diseases, or tuberculosis).

\section{Health Maintenance Activities}

Thirty-six percent of the companies surveyed reported that they provided preventive health or screening activities for their employees, often on company time ( $71 \%$ "always", $24 \%$ "sometimes"). Eleven companies had provided breast cancer education one or more times.

Almost half ( $46 \%)$ of the respondents said that they considered health education for employees and staff an appropriate function of companies such as theirs. Twenty-six percent did not think it an appropriate function and twenty-eight percent were not sure.

\section{Responsibility for Hiring}

The final decision to hire women with a history of breast cancer was seldom made by a medical practitioner (15\%). Most of ten, the personnel director made the decision (42\%). The future supervisor (26\%) and other company personnel such as a vice president (17\%) were others cited as responsible for the final decision. 
Regardless of who was the final decision maker, $81 \%$ of the respondents consulted with other person(s) before making such a decision. In $25 \%$ of the cases, this other person was the applicant's personal physician.

\section{Cancer Policies}

Though no company at the time of the survey had an explicit cancer policy, some respondents did know of other companies having such policies. Seven percent knew of companies requiring prospective applicants to be five years sympton-free of cancer before they would hire them. Thirteen percent said they did prefer, al though did not require, persons with a history of malignancy to be symptom-free for five years.

\section{The Employer (Factor $\$ 6$ )}

The respondants themselves were persons holding mid or upper level positions ( $14 \%$ company presidents, vice presidents or agency directors; $24 \%$ personnel directors; $19 \%$ other administrative/managerial; $18 \%$ personnel managers), with a substantial amount of work experience. Their median number of years in personnel work was 10 , with a median of 5 years in their current position as the person with major responsibility for hiring.

They were a well-educated group, $62 \%$ having a college degree (BA, BS) or higher; $84 \%$ had family incomes over $\$ 16,000$ annually. The median age of respondents was 39 . All were white and $79 \%$ were male.

\section{Experience with Breast Cancer}

Many respondents had experience with women with breast cancer both at work and among friends and family members. Three-fourths knew someone personally who had had breast cancer, and almost half had had employees leave work for treatment of this disease. Of the 27 respondents who had employees leave work for this reason, $48 \%$ reported that the women were absent from work on the average fewer than 8 weeks. Thirty-seven percent reported the usual absence of employees for treatment of breast cancer was between 8 and 13 weeks. One quarter of the respondents said that their companies had hired new employees with a history of breast cancer; $29 \%$ said that their companies had not, and $46 \%$ did not know if they had.

\section{Knowledge about Breast Cancer}

Many of the respondents had incomplete knowledge about breast can- 
cer. While $88 \%$ knew, correctly, that contact with someone who has cancer cannot cause the disease, $75 \%$ thought, incorrectly, that a blow to the breast could cause breast cancer. Only half of the respondents knew that women aged 45 to 60 were those most likely to develop breast cancer.

\section{Testing the theoretical model}

The 13 variables which together comprised the 3 major components examined in this research (company factors, company policies and employee attributes) were first correlated separately with actual hiring practice (Table 1). (See following page for Table 1). These correlations suggested that items from each of the three major independent variable categories would, when combined, yield the strongest explanation of hiring practice.

Trying a number of stepwise regression models using different combinations of the factors shown in Table 1 yielded a group of eight variables, five of them significant at the p<.05 level. All eight factors, along with their beta values, are shown in Table 2. The principal factors predicting whether or not a company had ever hired women with a history of breast cancer appear to be: size of company; ievel oi sick leave benefits; company involvement in the payment of medical insurance premiums; employer's education and personal experience with women with a history of breast cancer. These factors together explain $69 \%$ of the variance in companies hiring practices, The employers' level of knowledge about breast cancer, as well as their sex and age, plus the percentage of the company that is female, when looked at in combination with other variables, have little impact on hiring practices. (Table 2 follows Table 1 ).

Responsibility for decision making (medical or non-medical) is dependent on company factors, primarily type company and percentage of employees who are women, rather than policy factors such as sick leave. The type decision maker (medical or non-medical) does not appear to be an important predictor of the hiring of a woman with a history of breast cancer.

\section{Discussion}

Though the factors entered into the regression model to explain hiring practices are those set forth in the theoretical model (Fig. 1), some of the individual relationships to the dependent variable, as indicated by beta values, are surprising. 
TABLE 1: COEFFICIENTS FOR SELECTED VARIABLES WITH HIRING PRACTICE

\begin{tabular}{|c|c|c|c|}
\hline Variable & Coefficient & P value & Implied Relationship \\
\hline Type Company & .32 & .028 & $\begin{array}{l}\text { Non-industrial - have not } \\
\text { hired } \\
\text { Industrial - have hired }\end{array}$ \\
\hline Size Company & .52 & .001 & $\begin{array}{l}\leqslant 225 \text { employees-have not } \\
\text { hired } \\
>225 \text { employees-have hired }\end{array}$ \\
\hline $\begin{array}{l}\text { Percent of } \\
\text { employees who } \\
\text { are women }\end{array}$ & -.23 & .085 & $\begin{array}{l}\text { Less than } 50 \% \text {-have hired } \\
\text { More than } 50 \% \text {-have not } \\
\text { hired }\end{array}$ \\
\hline $\begin{array}{l}\text { Company medical } \\
\text { personnel }\end{array}$ & .38 & .011 & $\begin{array}{l}\text { No medical personnel-have } \\
\text { not hired } \\
\text { Have medical personnel- } \\
\text { have hired }\end{array}$ \\
\hline Sick leave & -.48 & .002 & $\begin{array}{l}\text { Low sick leave-have hired } \\
\text { High sick leave-have not } \\
\text { hired }\end{array}$ \\
\hline Insurance & .11 & .254 & ------ \\
\hline $\begin{array}{l}\text { Medical history } \\
\text { required }\end{array}$ & .39 & .009 & $\begin{array}{l}\text { Not required-have not hired } \\
\text { Required-have hired }\end{array}$ \\
\hline $\begin{array}{l}\text { Personal experi- } \\
\text { ence of employer } \\
\text { with breast cancer }\end{array}$ & -.05 & .392 & ------- \\
\hline $\begin{array}{l}\text { Knowledge about } \\
\text { breast cancer }\end{array}$ & .17 & .165 & -------- \\
\hline $\begin{array}{l}\text { Work experience } \\
\text { of employer with } \\
\text { breast cancer }\end{array}$ & .12 & .246 & ------ \\
\hline Entoloyer educ. & .47 & .002 & $\begin{array}{l}\text { Less education-have not hired } \\
\text { More education-have hired }\end{array}$ \\
\hline Employer sex & -.35 & .016 & Male-hired; Female-not hired \\
\hline Employer age & .04 & .399 & --- \\
\hline
\end{tabular}


TABLE 2: PREDICTORS OF HIRING PRACTICE

\begin{tabular}{|c|c|c|c|c|}
\hline Item & $F$ & Beta & $p$ & Implied Relationship \\
\hline \multicolumn{5}{|l|}{ COMPANY FACTORS } \\
\hline Size Company & 8.64 & .38 & .025 & $\begin{array}{l}\leq 225 \text { employees-not hired } \\
>225 \text { employees-hired }\end{array}$ \\
\hline \multicolumn{5}{|l|}{ COMPANY POLICIES } \\
\hline Sick leave ${ }^{a}$ & 12.89 & -.51 & .005 & $\begin{array}{l}\text { Low sick leave-hired } \\
\text { High sick leave-not hired }\end{array}$ \\
\hline Insurance ${ }^{b}$ & 4.49 & .29 & .05 & $\begin{array}{l}\text { Low insurance-not hired } \\
\text { High insurnace-hired }\end{array}$ \\
\hline \multicolumn{5}{|l|}{ EMPLOYER ATTRIBUTES } \\
\hline Education & 9.46 & .49 & .025 & $\begin{array}{l}\text { Less education-not hired } \\
\text { More education-hired }\end{array}$ \\
\hline Sex & 2.30 & .24 & NS & ------- \\
\hline Age & 2.40 & .22 & NS & ------ \\
\hline \multicolumn{5}{|l|}{$\begin{array}{l}\text { Personal ex- } \\
\text { perience with } \\
\text { women who } \\
\text { have had }\end{array}$} \\
\hline breast cancer & 4.27 & -.28 & .05 & $\begin{array}{l}\text { Less experience-hired } \\
\text { More experience-not hired }\end{array}$ \\
\hline Knowledge & .30 & .08 & NS & ------- \\
\hline TOTAL FOR THE REGR & SSION: & $\begin{array}{l}r^{2}=.69 \\
p<.001\end{array}$ & $F=6.36$ & degrees of freedom $=8 / 23$; \\
\hline
\end{tabular}

\footnotetext{
$a_{\text {Sick leave low }}=$ no paid sick leave days, no policy, some employees do not get sick leave, 10 or fewer days per year; high = 11 plus days per year

${ }^{b}$ Insurance low = company not involved or pays only part of premium for employees; high = company pays entire premium
} 
Knowledge about breast cancer does not seem to be a predictor of hiring decisions. Health educators and others have known for a long time that increasing knowledge or providing information to individuals about disease does not necessarily affect their own health behaviors or their behavior toward others. This lack of a relationship between knowledge and behavior seems to be borne out in this case as well. Both organizational factors, such as a company's size, and individual factors, such as employer's subjective experience with cancer patients, take precedence over the amount or accuracy of their knowledge about either the disease or the extent of its surgical disability in predicting their hiring behavior. The smaller a company and the more personal experience an employer has with breast cancer, the less likely women with a history of this disease are to be hired.

Company policies regarding sick leave (number of paid sick leave days the company grants employees annually) and type medical insurance (how involved the company is in payment of medical premiums) are also important predictors of hiring practices, but they operate in opposite directions from one another. That is, the more generous a company's sick leave benefits for its employees are, the less likely it is to hire a woman with breast cancer; however, the more comprehensive the medical insurance plan a company has for its employees, the more likely it is to hire such women."

The fact that $69 \%$ of the variance in hiring is explained by com-

* A possible explanation for this seeming contradiction may be that since direct costs to the company of sick leave are much greater than the direct company costs of medical insurance, the financial risk of hiring someone with a history of breast cancer, when viewed in terms of effect on the company's insurance rates, may indeed be quite small. Further, if the insurance coverage is the minimum offered by the insurance underwriter, then the actual premium paid may be as small or smaller in those companies with fuller coverage but who pay only part of the premium (employees paying the other part). Thus it may well be that those companies more likely to hire women with a history of breast cancer may actually pay the entire medical insurance premium for their employees, but it may be quite small; in turn, these may be the very companies which provide less generous sick leave benefits for their employees. The cost of premiums for group medical insurance, of course, are affected by many factors: the total number of employees; the percentage of employees who are women (acturial data are different for men and women); and the predominant type of employee (management and production employees, for example, are exposed to different kinds of heal th risks). 
pany factors, policies and the employer is noteworthy. The other factors in the model which could not be tested, women's individual medical and psychosocial conditions, almost certainly account for a substantial part of the remaining variance.

The mode1, we conclude, does have merit in explaining hiring practices for women with a history of breast cancer. Though some factors have been found to be stronger than others, the basic scheme of societal context, organizational level (company factors) and individual characteristics (of both the employer and the applicant) appears to be a sound one.

Finally, the variable "decision-making responsibility (medical or non-medical)" essentially was erased from the model. It appears that regardless of what type role the person who makes the final decision occupies, the influence of factors (e.g. a company's sick leave benefits' or the employer's personal experience with cancer) other than the applicant's actual medical condition is strong in the judgments made about individuals' suitability for employment.

The lack of specific medical policies and the influence of the employer's personal experience suggest that subjective, rather than medical and company, criteria take precedence in the decision to hire individuals with past medical or surgical disabilities. Whether these same factors would predict a similar outcome in the case of women with other handicaps or medical conditions remains to be explored. Whether the same criteria would emerge as predictive of the hiring of men with similar medical histories (e.g. former cancer patients) is also problematic, although Reynolds' study (1977) suggest that they would.

\section{Conclusions}

The results of this research indicate that the theoretical model developed to explain the decision to hire or not to hire women with a history of breast cancer can be a useful tool, especially in generating specific hypotheses to be tested by more rigorous future designs. That such a large amount of the variance in the dependent variable ("hiring practices") could be explained by organizational factors and the personal characteristics of the employer has at least two major implications.

First, the finding that the employer's personal experience with such women is an important element in whether they will be hired has disturbing discriminatory overtones. Subjective employment selection on the basis of personal experience is not only unfair to job appli- 
cants or employees but also to the company which loses potential workers. If medical criteria are used in hiring and/or firing, these standards should relate to individuals' abilities to perform specified jobs. That is, disability in the work place should be defined as a functional inability to perform in some areas (Davis, 1978). If occupational physicians or nurses are consulted or, likewise, personal physicians, they should be asked to make medical judgments about people's current physical conditions and whether they are capable of carrying out the jobs to be performed, rather than simply asked for a prognosis about the likelihood of future illnesses. The use of any other criteria suggest idiosyncratic standards which come dangerously close to the ofttimes ill-defined explanations used in rationalizing discriminatory practices based on racism, sexism or agism.

Hanks, in proposing nondiscriminatory medical standards, states: "If employees are medically capable of performing fully and safely work in question at time of hire, the only valid medical measure relative to current work-performance and risk has been met." (Hanks, 1977: 187) He goes further in suggesting that society must develop compensatory mechanisms that will relieve industry of part of the financial burden for degenerative and chronic disease which it is presently held responsible for. Reynolds (1977) suggests that insurance companies are also prime targets for remedial education and/or legislation. They set the rates which may influence employers to screen cancer patients differently on the basis of an expected (but not empirically confirmed) increase in absenteeism or a greater need for medical treatment.

Secondly, many of the determinants of the hiring decision are external to the individual wotnan with a history of breast cancer. Regardless of her particular condition, much of the decision about whether she is employed appears to be determined by factors beyond her control. Thus rehabilitation programs which focus on preparing women with a history of breast cancer to return to work are inadequate at best, and Inappropriate at worst. Education programs must aim at a target population larger than simply "cured" cancer patients. Not only must they help prepare women who are able to work again after surgery to deal with potential deterrants in the employment situation arising from possible prejudices against them as cancer "carriers" or "handicapped" workers, but they must also work with employers in helping them apply non-discriminatory medical standards. In addition, it is possible that returning breast cancer patients may face additional problems as a result not only of their medical condition but also, possibly, because they are women or, even more specifically, usually older women returning to the job market, often after an absence of many years. 
As has been mentioned above, insurance companies are another target of educational programs if they are proceeding on out-moded medical knowledge, conservative survival rate statistics, or labor force statistics unadjusted for changes in women's roles. Davis has suggested that standards applied to the employment of the "medically handicapped" be based on an individual's record of disability days and crisis events, rather than on "disability category", a form of labeling which can affect whether medically handicapped persons are accepted into vocational, educational or other programs (1978).

Since knowledge alone is not enough to effect the kinds of change proposed above, more research such as Alexander's $(1975,1977)$ must be done in order to demonstrate to employers that discriminatory medical standards are not in either the company's or the worker's best interests. The relationships between amount of sick leave taken, medical insurance costs to the company, and persons hired with certain disease conditions, need to be studied further. Since the hiring decision appears to be influenced by employer attributes rather than knowledge, more indepth work on reactions to the causes and consequences of a disease, rather than the amount or type of knowledge society has about it, needs to be undertaken.

Finally, the research reported on here did not include a comparison group of male cancer patients. Future research which sought to address whether women with a history of breast cancer faced an additional source of discrimination merely because they were working women, and not only from the stigmatization or fear caused by the disease, should incorporate into the research design a similar group of male workers returning to old jobs, or beginning new ones, after a series of treatments or extensive surgery for cancer. There is no reason that similar research to that described here could not be used to tease apart the effects of gender, conditon and other factors (e.g. age) known to contribute to discriminatory hiring practices. While in the present study there appeared to be no effect of employer's sex on the variation observed in hiring practices, the number of women personnel managers in this sample was really too small to adequately examine the interaction between sex of employer and of cancer patient returning to work. A study incorporating this research question would also be an interesting extension of the research reported on here. 


\section{References}

Alexander, R.W.

Marda, A.S.

Walker, R.J. 1975

Alexander, R.W.

Brennan, J.C.

Marda, A.S.

Walker, R.J. 1977

\section{California}

1975

Davis, C.

1978

Feldman, Frances L. 1978

Hanks, T.G. 1977

Jenkins, C.D.

Zyzanski, S.J. 1968

MkKenna, R.J. 1974

New York

1973
"The validity of preemployment medical evaluations." Journal of Occupational Medicine 17: 687-692.

"The value of preplacement medical examinations for nonhazardous 1ight duty work." Journal of Occupational Medicine 19:107-112.

Assembly Bill 1194, Chapter 431, Sections 14111412 of the Labor Code amended, approved by the Governor, August 28, 1975.

Roundtable Report. Women and Health Roundtable: Vol. II, Number 12.

"Work and cancer health histories: A study of the experiences of recovered blue-collar workers: Findings and implications." California Division, American Cancer Society, San Francisco, California.

"Medical standards for employment in relation to non-discrimination laws." Journal of Occupational Medicine 19:181-187.

"Dimensions of belief and feeling concerning three diseases, poliomyelitus, cancer, and mental illness: a factor analytic study." Behavioral Science 13:372-381.

"Employability and insurability of the cancer patient." A paper prepared for the American Cancer Society.

Flynn Act, Chapter 988, Laws of 1974 in Regular Sessions, 1973-1974, March 6, 1973, 4524B. 
Tokarski, S.S. Skarzynski, J. Smith, L.

Seboda, B. 1976

Voelz, G.L. Spiekard, J.H. 1975

Wakefield, J. 1970

Weinstock, M. Haft, J.

1974

Wheatley, G. M. Cunnick, W. R. Wright, B.P. vankeuren, D. 1974

Wil1iamson, S.M. 1971
"Not all illnesses are handicaps." Employee Relations Law Journal 2:66-85.

"Preemployment medical evaluation by questionnaire." Journal of Occupational Medicine 17: 687-692.

"The social implications of cancer." Radiography 36:93-95.

"The effect of illness on employment opportunities." Archives of Environmental Health $29: 79-83$.

"The employment of persons with a history of treatment for cancer." Cancer 33:441-445.

"18 years experience without preemployment examinations." Journal of Occupational Medicine 13:465-467. 